\title{
Does Minimally Invasive Spine Surgery Minimize Surgical Site Infections?
}

\author{
Arvind Gopalrao Kulkarni, Ravish Shammi Patel, Shumayou Dutta \\ Mumbai Spine Scoliosis \& Disc Replacement Centre, Orthopaedics Department Bombay Hospital \\ and Medical Research Centre, Mumbai, Mumbai, India
}

Study Design: Retrospective review of prospectively collected data.

Purpose: To evaluate the incidence of surgical site infections (SSIs) in minimally invasive spine surgery (MISS) in a cohort of patients and compare with available historical data on SSI in open spinal surgery cohorts, and to evaluate additional direct costs incurred due to SSI.

Overview of Literature: SSI can lead to prolonged antibiotic therapy, extended hospitalization, repeated operations, and implant removal. Small incisions and minimal dissection intrinsic to MISS may minimize the risk of postoperative infections. However, there is a dearth of literature on infections after MISS and their additional direct financial implications.

Methods: All patients from January 2007 to January 2015 undergoing posterior spinal surgery with tubular retractor system and microscope in our institution were included. The procedures performed included tubular discectomies, tubular decompressions for spinal stenosis and minimal invasive transforaminal lumbar interbody fusion (TLIF). The incidence of postoperative SSI was calculated and compared to the range of cited SSI rates from published studies. Direct costs were calculated from medical billing for index cases and for patients with SSI.

Results: A total of 1,043 patients underwent 763 noninstrumented surgeries (discectomies, decompressions) and 280 instrumented (TLIF) procedures. The mean age was 52.2 years with male:female ratio of 1.08:1. Three infections were encountered with fusion surgeries (mean detection time, 7 days). All three required wound wash and debridement with one patient requiring unilateral implant removal. Additional direct cost due to infection was $\$ 2,678$ per 100 MISS-TLIF. SSI increased hospital expenditure per patient 1.5-fold after instrumented MISS.

Conclusions: Overall infection rate after MISS was $0.29 \%$, with SSI rate of $0 \%$ in non-instrumented MISS and $1.07 \%$ with instrumented MISS. MISS can markedly reduce the SSI rate and can be an effective tool to minimize hospital costs.

Keywords: Minimally invasive surgical procedures; Decompression; Discectomy; Fusion; Surgical wound infections

\section{Introduction}

Surgical site infections (SSIs) are dreaded complications of spinal surgery with reported rates ranging from $0.09 \%$ to $16 \%$ [1-18]. Spinal SSIs can be catastrophic as they may be difficult to manage and may require prolonged hospitalisation, prolonged antibiotic therapy, repeated surgeries for wound debridement, or implant removal. SSIs in instrumented surgeries carry the added concern of adhesion of organisms to implants and biofilm formation,

Received Mar 22, 2016; Revised Apr 16, 2016; Accepted May 7, 2016

Corresponding author: Arvind Gopalrao Kulkarni

Mumbai Spine Scoliosis \& Disc Replacement Centre, Bombay Hospital

and Medical Research Centre, Mumbai 400020 India

Tel: +91-9892875490, Fax: +91-22-22080871, E-mail: drarvindspines@gmail.com 
which can complicate antibiotic treatment. SSI worsens the clinical outcomes, increases health care costs and can harm the reputation of the treating physicians and institutions. Minimizing SSIs is highly desirable.

Minimally invasive spine surgical (MISS) techniques reduce the required surgical corridor to access spine and lessen tissue destruction, blood loss, hospital stay, and postoperative morbidity [19]. Only a few studies have assessed the incidence of SSI following MISS [16-19]. We carried out this study to clarify the incidence of infections in MISS at our institution and to compare the results with established statistics in the literature. The findings also indicate that MISS may also simplify the management of acute infections.

\section{Materials and Methods}

We performed a retrospective analysis of prospectively collected data after getting permission from our Institutional Review Board. We analysed all consecutive patients that underwent minimal invasive spine surgery from January 2007 to January 2015. MISS was defined as surgeries performed with tubular retractor systems aided by microscopy [16]. All patients were operated on at a single centre by the senior author. Patients with less than 12 months of follow-up were excluded.

All procedures were performed using tubular retractors 16, 18, and $22 \mathrm{~mm}$ in diameter (METRx System, Medtronics, Memphis, TN, USA). As a rule, the preoperative antibiotic (third generation Cephalosporin) was given 1 hour prior to the surgical procedure [8]. All surgeries were performed with the patient in the prone position under general anaesthesia. We followed the standard technique of scrubbing, painting, and draping. The surgeries were performed under a laminar air-flow system. The microscope and the image-intensifier were draped appropriately with sterile drapes. Tubular discectomies (MED) were performed using 16- and 18-mm diameter tubes, tubular decompressions (MED-S) with 18-mm tubes and TLIFs (MIS-TLIFs) through the 22-mm tubes. Antibiotics were repeated intraoperatively for surgeries lasting more than 4 hours. Postoperatively antibiotic was repeated only once after surgery in case of non-instrumented surgeries. For instrumented surgeries antibiotics (third generation Cephalosporin and Aminoglycoside) were continued for 48 hours. Patients that underwent noninstrumented surgeries were mobilised 5-6 hours after surgery and those that had an instrumented surgery were mobilised the next day after surgery. Patients with dural tears and cerebrospinal fluid leaks were mobilised on day 1 postsurgery.

For the identification of the patients with infections, we followed the U. S. Centers for Disease Control and Prevention classification [20]. Postoperative infection was defined on the basis of clinical features that included persistent soakage from the wound site, unexpected back pain, elevated inflammatory parameters, and results of bacteriological analysis. All patients with infections were considered fully recovered only after two consecutive negative inflammatory markers obtained over an intervening period of at least 15 days and accompanied by clinical and radiological improvement.

A MEDLINE search was conducted with keywords relevant to spinal infections. Relevant articles were segregated and a range representative of such cohorts of open spine surgery data was determined. This was compared with the results obtained with our experience of MISS.

Direct costs borne by patients were collected from medical billing department for index cases as well as cases with SSI. Direct costs included surgical supplies (implants and disposables), room charges, professional fees, inpatient services (physiotherapist, dietician, and occupational therapy), cost of medicines, diagnostic investigations. Additional costs for revision due to complications other than SSI were excluded. Indirect costs were not taken into consideration.

\section{Results}

A total of 1,043 patients (Table 1) were included. The mean age of patients was 52.2 years (range, 19-91 years). The male:female ratio was 1.08:1. Overall MED for disc herniations were done in 400 cases, MED-S for stenosis in 363 (343 single level and 20 two level) and MIS-TLIF for 280 (253 single level and 27 two level). Mean operative time for MED was $60 \pm 25.4$ minutes, MED-S (for each level) was $80 \pm 18.6$ minutes, MIS-TLIF (for each level) was $210 \pm 43.2$ minutes. Mean operative blood loss for MED was $60 \pm 25 \mathrm{~mL}$, MED-S (for each level) was $70 \pm 21$ $\mathrm{mL}$, and MIS-TLIF (for each level) was $110 \pm 38.2 \mathrm{~mL}$. The elapsed time between the index surgery and detection of infection ranged from 4 to 10 days.

Three cases were diagnosed to have deep incisional infection (Table 2). 
Table 1. Summary of patients undergoing minimal invasive spine surgery

\begin{tabular}{|c|c|c|}
\hline Demographic data & $\begin{array}{c}\text { No. of } \\
\text { patients } \\
(\%)\end{array}$ & $\begin{array}{c}\text { No. of } \\
\text { infections } \\
(\%)\end{array}$ \\
\hline \multicolumn{3}{|l|}{ Sex } \\
\hline Male & $542(52)$ & 0 \\
\hline Female & $501(48)$ & $3(0.6)$ \\
\hline \multicolumn{3}{|l|}{ Region of spinal surgery } \\
\hline Cervical & 2 & 0 \\
\hline Thoracic & 2 & 0 \\
\hline Lumbar & 1,039 & $3(0.29)$ \\
\hline \multicolumn{3}{|l|}{ Type of procedure } \\
\hline Tubular discectomy (MED) & $400(38.3)$ & 0 \\
\hline $\begin{array}{l}\text { Tubular decompression } \\
\text { (MED-S) }\end{array}$ & $363(34.8)$ & 0 \\
\hline MIS-TLIF & $280(26.9)$ & $3(1.07)$ \\
\hline \multicolumn{3}{|l|}{ Levels operated } \\
\hline 1 Level & $996(95.5)$ & $3(0.3)$ \\
\hline 2 Level & $47(4.5)$ & 0 \\
\hline
\end{tabular}

MIS-TLIF, minimally invasive transforaminal lumbar interbody fusion.

\section{Case 1}

An 89-year-old diabetic female patient underwent a L4L5 MIS-TLIF for degenerative spondylolisthesis with stenosis. Surgery was uneventful but lasted 4.5 hours, which markedly exceeded the mean operative time for such an operation. She developed a deep infection that became apparent as a purulent discharge from the wound 4 days after index surgery. Culture of the pus grew Staphylococcus aureus. The infection was treated successfully with thorough debridement and a 6-week course of intravenous antibiotics. Patient recovered with Oswestry disability index (ODI) score, visual analog scale (VAS) ${ }^{\text {back }}$ and VAS ${ }^{\text {leg }}$ scores of $52 \%, 66.7 \%$, and $75 \%$, respectively, at 3 years of follow-up, which were indicative of improvement.

\section{Case 2}

A 75-year-old diabetic female patient underwent L5-S1 MIS-TLIF for spondylolytic spondylolisthesis. During surgery, a guide wire used for the insertion of the right L5 pedicle screw accidentally pierced the vertebral body into the abdomen. The wire was retrieved safely and successfully. Although the immediate postoperative period was

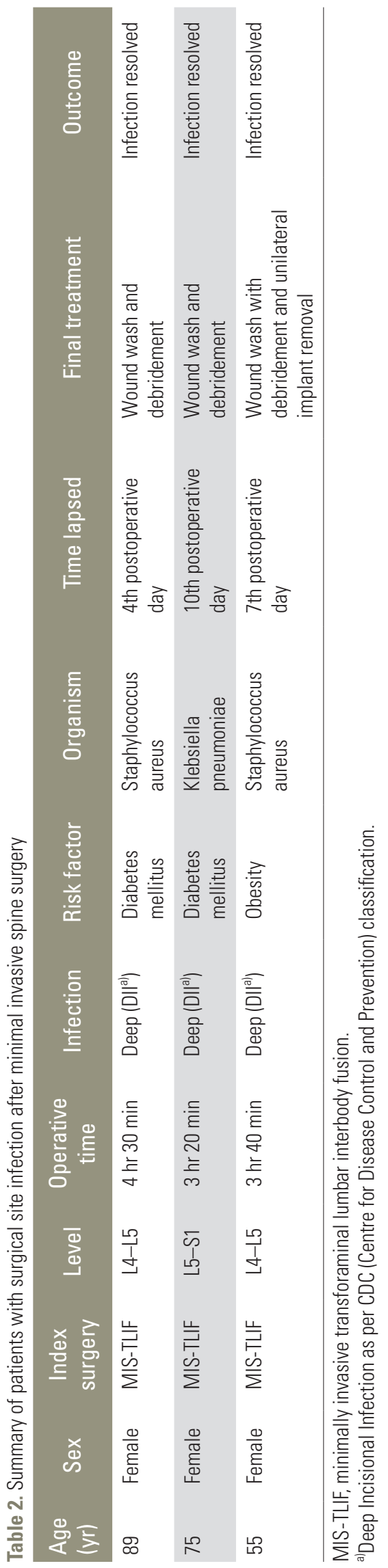


Table 3. Cost analysis

\begin{tabular}{lc}
$\begin{array}{l}\text { Type of procedure } \\
\text { MED }\end{array}$ & $\begin{array}{c}\text { Average direct costs } \\
\text { (range) }\end{array}$ \\
MED-S & $\$ 3,184(\$ 1,310-\$ 5,600)$ \\
\hline One-level & $\$ 3,294(\$ 1,317-\$ 5,856)$ \\
\hline Two-levels & $\$ 4,182(\$ 2,252-\$ 6,568)$ \\
\hline MIS-TLIF & \\
\hline One level & $\$ 5,270(\$ 4,294-\$ 6,320)$ \\
\hline Two-levels & $\$ 6,684(\$ 5,784-\$ 7,780)$ \\
\hline Additional expenses due to SSI & $\$ 2,500(\$ 2,000-\$ 2,815)$ \\
\hline
\end{tabular}

All costs mentioned here are in U.S. dollars (\$).

MIS-TLIF, minimally invasive transforaminal lumbar interbody fusion; SSI, surgical site infections.

uneventful, she developed a serosanguinous discharge from the wound on postoperative day 10. Urgent debridement, wound washing, and primary closure over a drain were performed. Intravenous antibiotics were initiated for 6 weeks as per the culture sensitivity report (s/o Klebsiella pneumoniae-a known commensal in the gut and pelvis/ abdomen) and recovered without need for further surgery. One year after index surgery, $\mathrm{X}$-rays and computed tomography scan revealed a successful fusion with significant ODI (54\%), VAS ${ }^{\text {back }}(71.4 \%)$, and VAS ${ }^{\text {leg }}(66.7 \%)$ improvements.

\section{Case 3}

A 55-year-old, obese African woman underwent a L4-L5 MIS-TLIF for degenerative spondylolisthesis. Intraoperatively, in view of an excellent bone stock, insertion of pedicle screws was a challenge and we had to resort to use power-drill to create tracks for pedicle screws through the tough bone. This generated a lot of thermal damage to the surrounding soft tissues resulting in necrosis. This probably led to deep infection that became apparent as a purulent foul-smelling discharge from one of the right-sided key-holes on postoperative day 7. During reoperation the left sided implants were unaffected and were retained. Due to the colossal spread of infection on right, unilateral implant removal was done. She recovered from the incident with a 6-week course of intravenous antibiotics (as per culture sensitivity-organism isolated was Staphylococcus aureus). Dynamic X-rays taken 1.5 years after surgery showed successful fusion with no instability.
Average direct costs for index surgeries are summarized in Table 3. Additional direct costs due to infections for case 1,2 , and 3 were $\$ 2,000, \$ 2,815$, and $\$ 2,685$, respectively. Approximate increase in health care expenditure per patient after SSI was 1.5 -fold. This produced an additional expenditure of $\$ 2,678$ per 100 MIS-TLIF.

\section{Discussion}

SSIs in spine surgery can lead to catastrophic complications and worsen clinical outcomes [1,2]. The reported rates of SSI in after open spine surgery vary from $0.7 \%$ to $16 \%$ [1-13]. Open spine surgeries are confronted with large incisions, extensive soft tissue dissection, and wider retraction. The resulting iatrogenic morbidity has been very well established [21]. Gradually, there has been a paradigm shift from the sub periosteal resection and excessive muscle retraction to soft tissue dilatation using the sequential dilators and tubular retractors. Since the inception of tubular retractors by Foley and Smith in the late 1990s, various authors have tried to determine the infection rates after MISS [14-18]. The reported rates are 0.09\% to $1 \%$ [16-18]. The probable reasons for reduced infection rates in MISS are the use of a small surgical corridor, reduction in the exposed surface area, and reduction in dead space [22]. Less muscle retraction means less ischemia, less necrosis, and better wound healing potential. More restricted surgical field leads to less exposure to potential pathogens and reduces disturbances of skin and skin flora as they are guarded by tubes [16]. The shorter hospital stay observed with MISS may also reduce the exposure to hospital-acquired pathogenic organisms. However, there are concerns regarding the challenges a surgeon faces during initial experience with these systems $[17,23]$. The longer operative duration and the steep learning curve may amend the infection rates observed at different centres. Hence a consensus statement can only be made after conclusive evidence of lowered SSI rates are established from centres and spine surgeons across the globe.

Most of the studies reported have encountered infections within first 12 months of surgery except some isolated reports in scoliosis surgery [24,25]. Hence, it is necessary to have an adequate follow-up postsurgery to validate the observed infection rates. We had included only those patients who had been followed up for more than 12 months. All infections that we encountered were in the early postoperative period (mean, 7 days). Most 
common organism encountered was S. aureus (two cases, $66.7 \%)$ which corresponds to the other studies $[9,13,16]$. The second case had an accidental penetration of guide wire beyond anterior vertebral wall into the abdomen, which was retrieved successfully but caused a K. pneumoniae infection postoperatively.

Infection rate with noninstrumented tubular surgeries was $0 \%$ and the infection rate with the instrumented surgery was only $1.07 \%$. Compared with the published open spine surgery cohorts, we obtained a 2 - to 16 -fold reduction in the infection rate. O'Toole et al. [16] evaluated SSI after MISS and reported an overall incidence of $0.22 \%$. Analysis of their data revealed an incidence of $0.10 \%$ in the non-instrumented and $0.74 \%$ with instrumented surgeries. Shousha et al. [18] in a large study of 4,350 cases of MISS noninstrumented surgeries observed an infection rate of $0.09 \%$ with noninstrumented surgeries. Similarly, a literature review by Parker et al. [15] that compared postoperative infection after minimally invasive and open TLIFs revealed a reduced incidence of SSI after MISS. However, McGirt et al. [14] observed that MISS was associated with lower rate of SSI in cases of two-level fusions with no statistically significant difference between open and MIS one-level fusion procedures. Nonetheless, our observations strengthen the conclusion that MISS reduces the SSI rate and also postoperative morbidity encountered by a patient victimized by infection. As compared to other published literature on MISS using similar minimal invasive techniques, lower infection rate in non-instrumented surgery as observed in our study may be due to sterile precautions in handling microscope and image intensifier. In MISS, image intensifier plays a major role in successful execution of MISS. In our practice, we drape only the top portion of the image intensifier and maintain its sterility throughout the surgical procedure. It is the lower portion of image intensifier that undergoes constant change in position that can be a potential source of contamination. We freshly drape the lower portion of $\mathrm{C}$-arm each time the image intensifier is positioned for a lateral exposure. Bible et al. [26] studied the sterility of operative microscopes and observed that microscopes are a significant source of contamination. Draping of the microscope using sterile drapes and use of aseptic precautions while handling the eye piece help reduce contamination. We change our gloves every time after manipulating the optical eye piece and avoid contact with the portion of drape above optical eye-piece. The laminar air flow system also helps in reduc- tion of infection rates to certain extent [27].

Infections after open spine surgery increase the health care utilisation cost by four-fold [28]. However, as observed in our study, additional direct costs of SSI per 100 index MIS-TLIF was just $\$ 2,678$. Another study reported a reduction of total health care cost of $\$ 98,974$ per 100 MIS-TLIF due to reduction in infection rates [15]. AlKhouja et al. [29] similarly reported a $2.54 \%$ to $33 \%$ reduction in cost between MISS and open spine surgery. Hence, in the present era of cost effectiveness and cost analysis, MISS holds a promising place in reducing the overall health care cost. In developing countries, the economic burden on the patients is enormous, since a large segment of the society is un-insured and patients bear the hospital expenses from their savings. Hence, it is crucial and obligatory to minimize morbidity as a result of postoperative wound infections and the associated health-care costs.

Patients requiring additional plastic coverage procedures, repeated surgeries, implant removal followed by subsequent salvage procedures have additional physical, social and financial repercussions. Patients with SSI undergoing MISS as index surgery will probably require less amount of such aggressive surgeries. The dead space created due to index surgery and the soft tissues exposed to infection are much less and adequate coverage can be obtained even with thorough debridement alleviating the need for secondary coverage procedures. Implant removal can be averted in cases of acute infections except late onset infections and Propionibacterium acnes $[1,6,10,12,25,30]$. A robust clinical surveillance and prompt recognition of clinical infection plays a major role in successful outcomes after SSIs. Due to presence of intact midline soft tissue curtain unilateral implants can be retained and better clinical outcomes can be obtained without need for salvage surgeries as observed in this study. However, longterm results of such interventions need to be studied in large nested case-control random trials.

This study had a few limitations. We did not have a control group of open spine surgery, as all such cases at our institution were performed using minimally invasive surgical techniques only. The surgeries that we performed routinely with open surgical techniques like deformity corrections, long segment fusions, and cervical laminectomies cannot serve as an appropriate control group. Also the number of infected cases in this series was so small, that a valid conclusion regarding the risk factors cannot 
be extracted. Moreover, the few cases presented here do not represent every situation that could arise in patients with SSIs. Large case-control trials are required for further evaluation.

\section{Conclusions}

Infection rate after tubular microscopic assisted spinal surgery was very low $(0.29 \%)$. Infection rate after noninstrumented MISS was 0\% and instrumented MISS fusion was $(1.07 \%)$. Minimally invasive technique markedly reduces (2- to 16-fold) the risk of postoperative infection when compared with other large open spine surgery series published in the literature. MISS can be an effective tool to minimize hospital costs.

\section{Conflict of Interest}

No potential conflict of interest relevant to this article was reported.

\section{References}

1. Beiner JM, Grauer J, Kwon BK, Vaccaro AR. Postoperative wound infections of the spine. Neurosurg Focus 2003;15:E14.

2. Olsen MA, Mayfield J, Lauryssen C, et al. Risk factors for surgical site infection in spinal surgery. J Neurosurg 2003;98:149-55.

3. Collins I, Wilson-MacDonald J, Chami G, et al. The diagnosis and management of infection following instrumented spinal fusion. Eur Spine J 2008;17:44550.

4. Valentini LG, Casali C, Chatenoud L, Chiaffarino F, Uberti-Foppa C, Broggi G. Surgical site infections after elective neurosurgery: a survey of 1747 patients. Neurosurgery 2008;62:88-95.

5. Olsen MA, Nepple JJ, Riew KD, et al. Risk factors for surgical site infection following orthopaedic spinal operations. J Bone Joint Surg Am 2008;90:62-9.

6. Pappou IP, Papadopoulos EC, Sama AA, Girardi FP, Cammisa FP. Postoperative infections in interbody fusion for degenerative spinal disease. Clin Orthop Relat Res 2006;444:120-8.

7. Friedman ND, Sexton DJ, Connelly SM, Kaye KS. Risk factors for surgical site infection complicating laminectomy. Infect Control Hosp Epidemiol 2007;
28:1060-5.

8. Kanayama M, Hashimoto T, Shigenobu K, Oha F, Togawa D. Effective prevention of surgical site infection using a Centers for Disease Control and Prevention guideline-based antimicrobial prophylaxis in lumbar spine surgery. J Neurosurg Spine 2007;6:3279.

9. Fang A, Hu SS, Endres N, Bradford DS. Risk factors for infection after spinal surgery. Spine (Phila $\mathrm{Pa}$ 1976) 2005;30:1460-5.

10. Mirovsky Y, Floman Y, Smorgick Y, et al. Management of deep wound infection after posterior lumbar interbody fusion with cages. J Spinal Disord Tech 2007;20:127-31.

11. Weinstein MA, McCabe JP, Cammisa FP Jr. Postoperative spinal wound infection: a review of 2,391 consecutive index procedures. J Spinal Disord 2000; 13:422-6.

12. Picada R, Winter RB, Lonstein JE, et al. Postoperative deep wound infection in adults after posterior lumbosacral spine fusion with instrumentation: incidence and management. J Spinal Disord 2000;13:425.

13. Gaynes RP, Culver DH, Horan TC, Edwards JR, Richards C, Tolson JS. Surgical site infection (SSI) rates in the United States, 1992-1998: the National Nosocomial Infections Surveillance System basic SSI risk index. Clin Infect Dis 2001;33 Suppl 2:S69-77.

14. McGirt MJ, Parker SL, Lerner J, Engelhart L, Knight T, Wang MY. Comparative analysis of perioperative surgical site infection after minimally invasive versus open posterior/transforaminal lumbar interbody fusion: analysis of hospital billing and discharge data from 5170 patients. J Neurosurg Spine 2011;14:771-8.

15. Parker SL, Adogwa O, Witham TF, Aaronson OS, Cheng J, McGirt MJ. Post-operative infection after minimally invasive versus open transforaminal lumbar interbody fusion (TLIF): literature review and cost analysis. Minim Invasive Neurosurg 2011;54:337.

16. O’Toole JE, Eichholz KM, Fessler RG. Surgical site infection rates after minimally invasive spinal surgery. J Neurosurg Spine 2009;11:471-6.

17. Ee WW, Lau WL, Yeo W, Von Bing Y, Yue WM. Does minimally invasive surgery have a lower risk of surgical site infections compared with open spinal surgery? Clin Orthop Relat Res 2014;472:1718-24. 
18. Shousha M, Cirovic D, Boehm H. Infection rate after minimally invasive noninstrumented spinal surgery based on 4350 procedures. Spine (Phila $\mathrm{Pa} 1976$ ) 2015;40:201-5.

19. Brodano GB, Martikos K, Lolli F, et al. Transforaminal lumbar interbody fusion in degenerative disk disease and spondylolisthesis grade I: minimally invasive versus open surgery. J Spinal Disord Tech 2015;28:E559-64.

20. Horan TC, Gaynes RP, Martone WJ, Jarvis WR, Emori TG. CDC definitions of nosocomial surgical site infections, 1992: a modification of CDC definitions of surgical wound infections. Infect Control Hosp Epidemiol 1992;13:606-8.

21. Kawaguchi Y, Matsui H, Tsuji H. Back muscle injury after posterior lumbar spine surgery: a histologic and enzymatic analysis. Spine (Phila Pa 1976) 1996;21: 941-4.

22. Fessler RG, O’Toole JE, Eichholz KM, Perez-Cruet MJ. The development of minimally invasive spine surgery. Neurosurg Clin N Am 2006;17:401-9.

23. Cheng JS, Park P, Le H, Reisner L, Chou D, Mummaneni PV. Short-term and long-term outcomes of minimally invasive and open transforaminal lumbar interbody fusions: is there a difference? Neurosurg Focus 2013;35:E6.
24. Emel E, Karagoz Guzey F, Guzey D, Seyithanoglu H, Sel B, Alatas I. Delayed infection 6 years after spinal instrumentation: a case report. Turk Neurosurg 2007; 17:116-20.

25. Lee JS, Ahn DK, Chang BK, Lee JI. Treatment of surgical site infection in posterior lumbar interbody fusion. Asian Spine J 2015;9:841-8.

26. Bible JE, O’Neill KR, Crosby CG, Schoenecker JG, McGirt MJ, Devin CJ. Microscope sterility during spine surgery. Spine (Phila Pa 1976) 2012;37:623-7.

27. Gruenberg MF, Campaner GL, Sola CA, Ortolan EG. Ultraclean air for prevention of postoperative infection after posterior spinal fusion with instrumentation: a comparison between surgeries performed with and without a vertical exponential filtered airflow system. Spine (Phila Pa 1976) 2004;29:2330-4.

28. Calderone RR, Garland DE, Capen DA, Oster H. Cost of medical care for postoperative spinal infections. Orthop Clin North Am 1996;27:171-82.

29. Al-Khouja LT, Baron EM, Johnson JP, Kim TT, Drazin D. Cost-effectiveness analysis in minimally invasive spine surgery. Neurosurg Focus 2014;36:E4.

30. Maruo K, Berven SH. Outcome and treatment of postoperative spine surgical site infections: predictors of treatment success and failure. J Orthop Sci 2014; 19:398-404. 